\title{
UBÚ PICASSO
}

\author{
POR \\ INOCENTE SOTO CALZADO \\ Universidad de Granada
}

\begin{abstract}
Ubú es un personaje — no nos atrevemos a definirlo como de ficción- materializado en 1896 por el escritor Alfred Jarry como protagonista de la pieza teatral Ubú rey, a la que seguirán diversas secuelas. Esta creación es definida por la crítica literaria como ejemplificación de la grosería del poder, de la violencia gratuita y de la miseria moral. Como tal, ha sido asociado con el trabajo gráfico de Pablo Picasso en el grabado datado en 1937 Sueño y mentira de Franco a la hora de recrear la figura del general sublevado Francisco Franco. Pero los modelos picassianos nos demuestran continuamente su polisemia.
\end{abstract}

Palabras clave: Picasso. Jarry. Ubu. Apollinaire. Maar. Guerra civil.

Ubu is a personage - we dare not define him as ficticious - materialized in 1896 by Alfred Jarry as the protagonist of his play Ubu Rex, followed by diverse sequels. This creation is defined by literary critics as an illustration of the grossness of power, of unfounded violence and moral misery. As such, it has been associated with Pablo Picasso's 1937 etching Dream and Lie of Franco in terms of its recreation of the figure of the rebellious General. Nevertheless, Picasso's models reveal that they are continually polysemantic.

Key words: Picasso. Jarry. Ubu. Apollinaire. Maar. Spanish Civil War.

Alfred Jarry (1873-1907) es el prototipo del escritor de vanguardia, capaz de romper todas las normas tanto en su arte como en su vida, y de romper las fronteras entre el arte y la vida, representando a sus propios personajes y a otros, presentándose con levita y zapatos de ciclista o descorchando champán a disparos ${ }^{1}$. En 1896 publicó su pieza Ubú rey, la más moderna sátira, con miserables personajes y míseras acciones, dividida en cinco actos. En el mismo año se produce su estreno en la escena con actores, en el Théâtre de l'Oeuvre, y en 1898 la representación se hará mediante marionetas en el Théâtre des Pantins, tal y como originalmente había sido previsto y querido por el autor. $\mathrm{Ni}$ que decir tiene que a estos estrenos les siguieron sus respectivos escándalos y polémicas, necesarias y se diría que imprescindibles, pues las nuevas ideas de Jarry en cuanto a escritura y puesta en escena obligará a gritar escandalizados a determinados tipos ${ }^{2}$.

El autor sitúa la obra en Polonia, o sea, en ninguna parte según su declaración, porque Ninguna Parte está en todas y, en primer lugar, en el país donde nos encontramos ${ }^{3}$. La obra se centra en la personalidad de Padre Ubú, bien secundado por Madre Ubú, y narra la ascen-

\footnotetext{
${ }^{1}$ Bretón, André, Antología del humor negro. Barcelona, 2002, p. 239

${ }^{2}$ Jarry, Alfred, Todo Ubú. Barcelona, 1980, p. 100.

${ }^{3}$ Jarry, Alfred, Op. cit., p. 26.
} 
sión al trono de Polonia de Ubú gracias a la conjura y al asesinato a sangre fría del rey Venceslao, que hasta dicho momento lo tiene por hombre de confianza. Un diálogo de Madre Ubú todavía en el primer acto define muy bien al personaje de su marido:

¡Oh, el traidor y el cobarde! ¡El vil y vulgar roñoso! ${ }^{4}$

Pero uno de los hijos del rey, junto a la reina, escapa a la masacre, y este hecho, unido a la cobardía y a los continuos crímenes que Ubú comete con el único fin de enriquecerse, precipitará la caída del arribista. En la escena séptima del cuarto acto, cuando Ubú ya ha perdido su trono y se encuentra escondido en una cueva, en medio del sueño se autodefine con estas palabras rebosantes del peculiar vocabulario jarriano:

Descerebrar, tomatar, cortar onejas, arrebatar riquezas y beber hasta morir. Esa es la vida de los salopines y la felicidad del Señor de las Phinanzas ${ }^{5}$.

Pero al final, huidos de Polonia, Madre Ubú, Padre Ubú y sus secuaces terminan la obra en un barco de regreso a Francia, prometiendo nuevas hazañas acordes a su catadura.

Desde su estreno, el personaje de Ubú se convirtió en mito y también en prototipo, especialmente para una Europa que iba a asistir a dos guerras mundiales y a la guerra civil española, y tanto autor como personaje permanecerían como referencia de varias generaciones de artistas de vanguardia ${ }^{6}$.

Si Ubú rey gozó de un gran predicamento literario, no le fue a la zaga, desde su nacimiento, la parte plástica. Los artistas nabis, aquellos pintores profetas seguidores de Gauguin, colaboraron junto a Jarry, pintando escenarios y diseñando máscaras, y ahí estaban Pierre Bonnard, Paul Sérusier, Tolouse-Lautrec, Vuillard y Paul Ranson. Año y mes más tarde del estreno con actores, ante el cambio de teatro y de planteamientos, Jarry trabajó en las marionetas junto al músico Claude Terrase y a Vuillard y Bonnard, que respectivamente decoraron la sala con excelentes colores y dibujaron siluetas en gris y negro ${ }^{7}$. La labor artística de Alfred Jarry en Ubú rey comprende además dibujos y grabados, publicados con la versión completa de la obra en los números de abril y mayo de 1896 de Livre d'Art, donde nos presenta la primera visualización del personaje, y acertadamente fija los rasgos esenciales de la personalidad gráfica de Ubú que han perdurado a través del tiempo, como por ejemplo en el grabado en madera que ilustró el programa de mano de la primera representación de 1896 en el Théâtre de l'Oeuvre, llamado Verdadero retrato del señor Ubú [fig. 1], y en Otro retrato del señor Ubú, dibujo reproducido por fotomecánica en la edición de 1896 [fig. 2], obras que Pablo Picasso (18811973) va a recordar en 1905 y a versionear de una manera muy especial en la hoja denominada Croquis: Ubú, Paco Durio, Renée Peron... [fig. 3] En ese laboratorio picassiano de bosquejos encontramos una colección de caricaturas, e incluso anotaciones junto a algunas de ellas, por lo que sabemos fácilmente que ese señor de cabeza redondeada, bigote, bombín y abrigo es Paco Durio, y que esa señora de perfil junto al perro es Renée Peron, pero no hay palabras bajo los seis dibujos que claramente nos remiten a los de Alfred Jarry (¿son las primeras imágenes de un proceso, en transformación todavía, sin alcanzar su fin?).

Picasso parece copiar en un principio la creación de Jarry, como evidencia la figura mostrada de cuerpo entero con sus detalles como la espiral en la panza del personaje y el arma difícilmente identificable que éste lleva bajo su brazo derecho, según el dramaturgo un bastón permanentemente metido en el bolsillo derecho ${ }^{8}$. Pero si nos detenemos un momento e inicia-

\footnotetext{
${ }^{4}$ Jarry, Alfred, Op. cit., p. 46.

${ }^{5}$ Jarry, Alfred, Op. cit., p. 85.

${ }^{6}$ Pariente, Ángel, Diccionario temático del surrealismo. Madrid, 1996. Pp. 187-188, especialmente las palabras de Maurice Heine en 1937.

${ }^{7}$ Cate, Phillip Dennis, «The Spirit of Montmartre», p. 63. En The Spirit of Montmartre. Cabarets, Humor and the AvantGarde, 1875-1905. New Jersey, 1996, pp. 1 a 93.

${ }^{8}$ Jarry, Alfred, Op. cit., p. 32.
}

$A E A$, LXXVIII, 2005, 312, pp. 353 a 368 

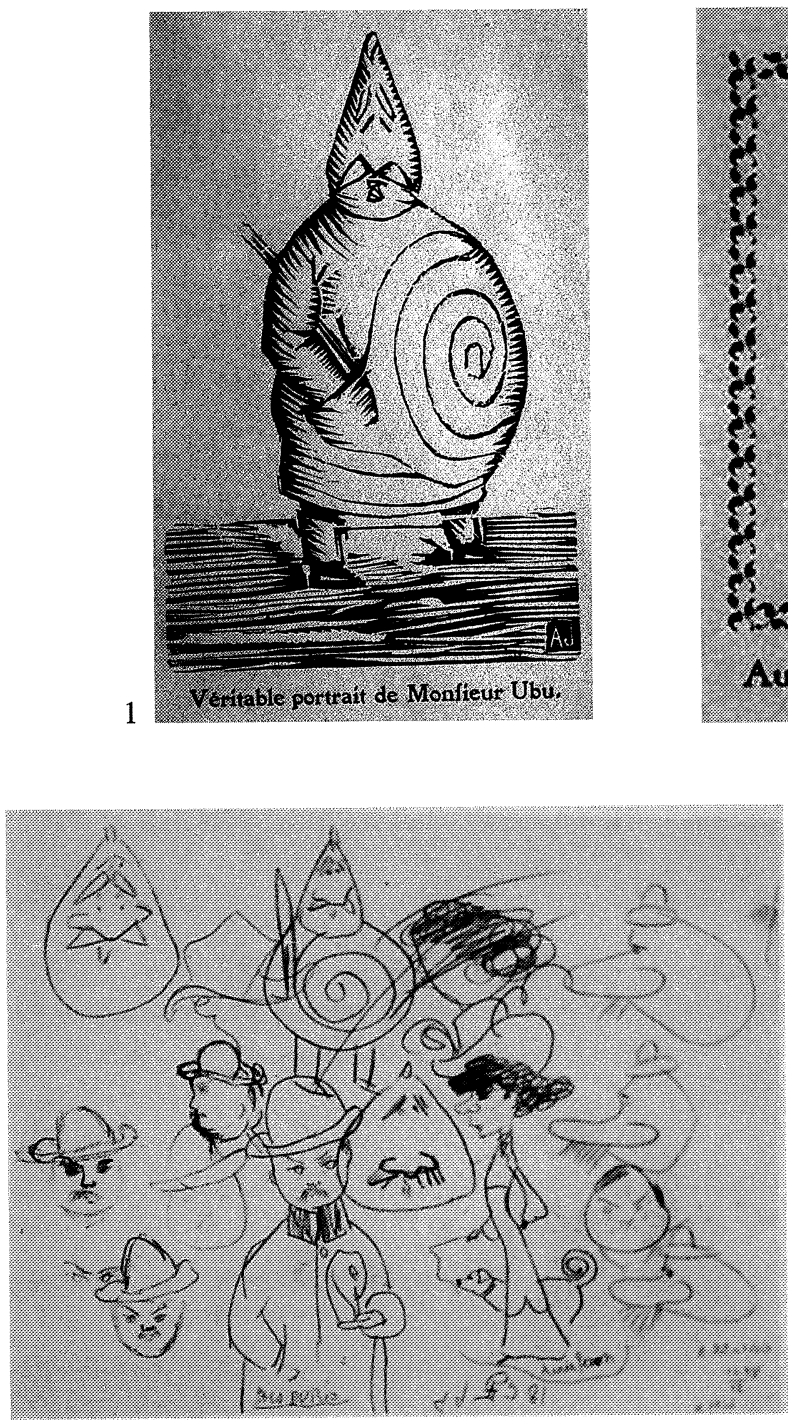

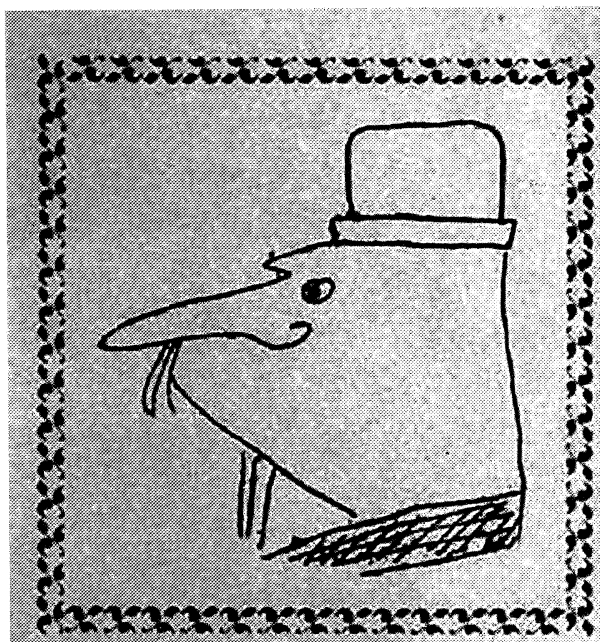

Autre Portrait de Monfieur Ubu.

3
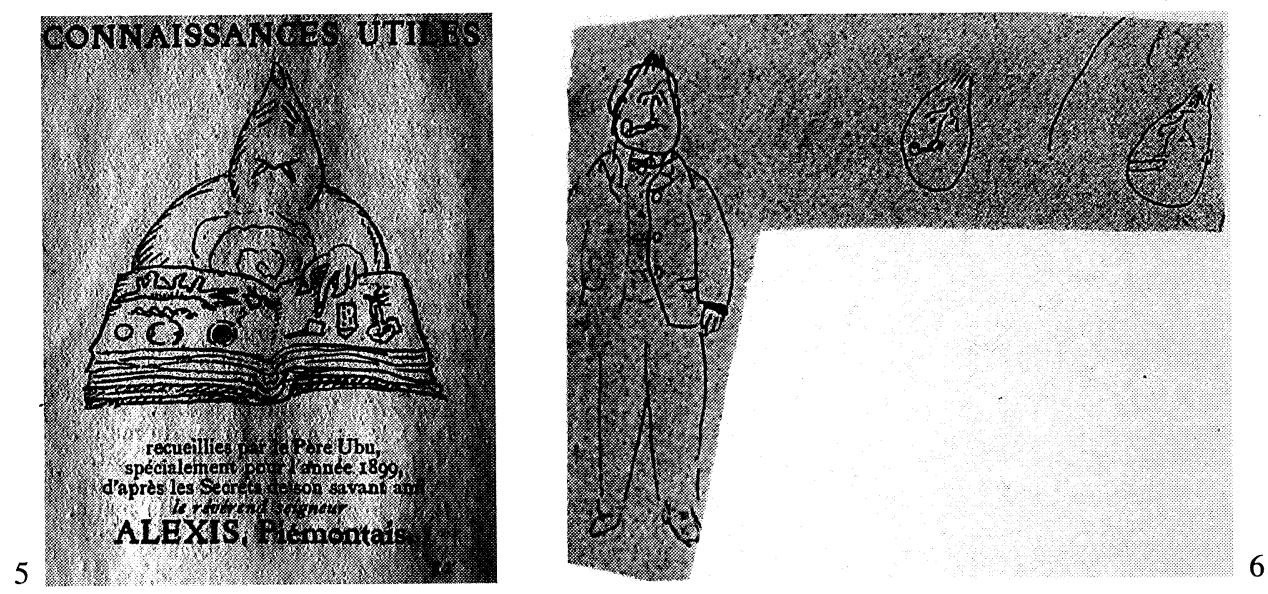

Lám. I.

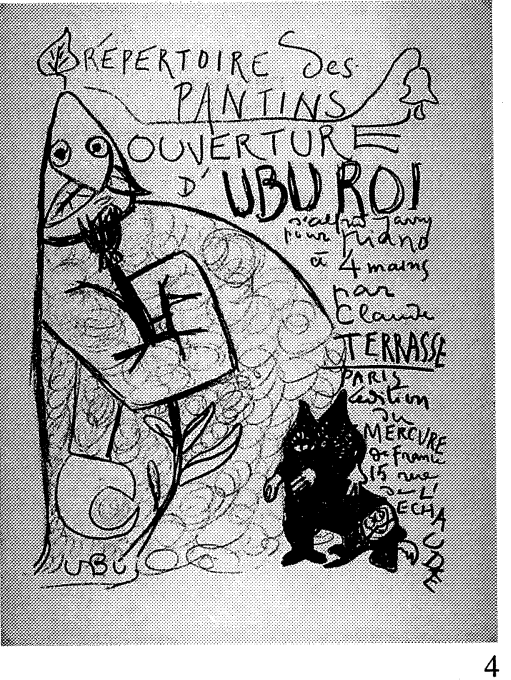


mos un somero análisis, nos percataremos de que el pintor ha exagerado la redondez del tronco y la forma de pera de la cabeza, y, más importante aún, lo que en Jarry no era más que una inexpresiva máscara se convierte en Picasso en un humanizado rostro capaz de transmitirnos incluso un cierto sentimiento de pena, de solidaridad con la desdicha del personaje (ojos, cejas, tamaño de la nariz y arqueamiento del bigote colaboran a ello formalmente). Y en esto insiste el malagueño, pues en la misma hoja encontramos dos nuevos bocetos que, despreocupándose del resto del cuerpo, nos representan la cabeza que ha dejado de ser máscara en sus manos. La cabeza de la izquierda parece centrarse en el dibujo de ojos y cejas; la cabeza que encontramos en el centro de la hoja de croquis diversos no sigue siquiera las formas que Jarry dispuso para cejas y bigotes, sino que las varía añadiendo líneas y alejándose aún más del original de partida, y por otro lado la ancha base de esta pera humana se nos muestra descomunal respecto a su escueta cúspide.

Igualmente, los tres perfiles dibujados por Picasso a la derecha de su hoja de croquis, que toman como punto de partida el perfil creado por Jarry en Autre portrait de Monsieur Ubu, incluido sombrero, se apartan de su modelo en el redondeo de sus líneas y volúmenes, huyendo de las formas angulosas e inquietantes, volviendo al esquema de la pera (base ancha, terminación estrecha) y dejándonos una amable caricatura, donde han desaparecido los pelos de la barbilla y se dibujan los del bigote como graciosas cerdas de un cepillo subnasal. La creación de Alfred Jarry, extravagante y extraña, toma como en otras ocasiones, conservando la estructura básica, un contenido nuevo en Picasso, mediante formas redondeadas y trabajo de algunos detalles.

La relación entre pera y cabeza proviene efectivamente de Alfred Jarry, aunque él no la explote gráficamente en un principio con la rotundidad de Picasso. El escritor la destaca literariamente, en el párrafo de introducción a Ubú rey, en uno de sus típicos juegos de palabras que abandonan la lógica buscando el humor, jugando con las palabras inglesas shake (sacudir, menear) y pear (pera) y dotando de una nueva personalidad al conocido dramaturgo inglés William Shakespeare, al mismo tiempo que lo emparenta con su creación y reconoce sus deudas de partida con Hamlet:

Así pues, el Padre Ubú meneó la pera, por lo que desde entonces los ingleses le llamaron Shakespeare, y habéis de él, bajo ese nombre, muchas hermosas tragedias por escrito ${ }^{9}$.

Jarry explota dibujísticamente este juego en las litografías de 1898, haciendo del bigote dos hojas y colocando otra hoja encima de la cabeza, exactamente como nos hemos acostumbrado a ver una pera [fig. 4]. Pierre Bonnard (1867-1947), cuando realiza las litografías para el $\boldsymbol{A l}$ manach du Père Ubu illustrè de 1899, sigue, con un dibujo más suelto y alegre, los esquemas gráficos de Alfred Jarry, pero relajándose en la representación de todas estas referencias, como podemos apreciar en la página doce de dicho almanaque [fig. 5].

Picasso relaciona cabeza y pera caricaturizando la propia caricatura de Ubú, buscando la relación con otra cabeza literaria, la de su amigo Guillaume Apollinarie (1880-1918), como podemos observar por la analogía con varias caricaturas del poeta, como en la hoja de dibujos Tres croquis de Guillaume Apollinaire, conservada en el Museo Picasso de París [fig. 6]. Efectivamente, el Padre Ubú meneó la pera y Picásso lo convirtió en Apollinaire, gran seguidor del propio Alfred Jarry y cultivador como él de la libertad y del humor en la literatura. El pintor convierte un retrato en imagen cómica, metamorfosis muy apreciada en sus trabajos de la época y especialmente en lo que se refiere a la imagen de su amigo poeta, al cual vemos ejercer en diferentes transfiguraciones de marinero, torero, académico, artillero, culturista, ana-

\footnotetext{
${ }^{9}$ Jarry, Alfred, Ubu roi ou les polonais. París, 1995, p. 15. El original francés dice así: Adonc le père Ubu hoscha la poire, dont fut depuis nommé par les anglois Shakespeare, et avez de lui sous ce nom maintes belles tragoedies par oscript. Traducción y nota de José-Benito Alique en Jarry, Alfred, Todo Ubú. Barcelona, 1980, p. 29.
}

AEA, LXXVIII, 2005, 312, pp. 353 a 368 
crónico papa moderno con reloj de pulsera e incluso barriguda cafetera ${ }^{10}$. Versatilidad y misterio de las ideas picassianas, con un especial gusto por la mixtura. Apollinaire había sido un gran amigo de Jarry -celoso vigilante incluso de sus excesos con el revólver en la mano-, al igual que otros poetas que formaban parte del círculo de amistades de Picasso, como Maurice Raynal o André Salmon, que como abnegados discípulos imitaban el vocabulario burlesco y la particular dicción del autor de Ubú ${ }^{11}$. Picasso se debía contar entre esta cohorte de admiradores de Jarry, o cuando menos espectador o conocedor, pues además de su particular versión gráfica sabemos que el pintor poseyó diversas ediciones e incluso manuscritos de la obra ubuesca ${ }^{12}$. Por otro lado, el pintor junto a su amigo Casagemas fue espectador de las marionetas de Ubú en su primer viaje a París, en el innovador teatro del cabaret Les 4z'Arts, en alguna de las sesenta y cuatro representaciones de $\boldsymbol{U} \boldsymbol{b u}$ sur la butte, una versión reducida a dos actos de $\boldsymbol{U} \boldsymbol{b} \boldsymbol{u}$ roi , que tuvieron lugar en el otoño de $1901^{13}$. Otra cosa bien distinta es que Picasso conociera personalmente a Alfred Jarry, aunque sí parece probado el hecho -de gran carga simbólica y poco más- de que Picasso conservó el arma de fuego de Jarry, que previamente le había confiscado Apollinaire en una trifulca.

Morirá Alfred Jarry en 1907. En el número 21 de Les Soirées de Paris, el 15 de febrero de 1914, aparecía un retrato de Alfred Jarry realizado por Picasso ${ }^{14}$ [fig. 7], aunque esto hemos de entenderlo sobre todo como un gesto de amistad hacia el propio Guillaume Apollinaire, que fue director de esta publicación en sus veintisiete primeros números, desde 1912 hasta la interrupción de su edición a causa de la guerra en $1914^{15}$. A diferencia de otras fotografías y dibujos que conocemos de Jarry, en ésta se nos muestra despeinado, quizás recordando los excesos que llevaron a su fin, convertido en modelo del escritor vanguardista, maldito.

Si algunos autores han hablado de la buena estrella crítica de Jarry en vida, ésta no es comparable a lo ocurrido con posterioridad. Posiblemente, la muerte del dramaturgo, al igual que su propia vida, contribuyó a convertir el personaje de Ubú en una idea universal, en una personificación más que en un personaje, patrimonio de todos. El marchante de obras de arte y editor de cuidados libros de artista Ambroise Vollard (1866-1939) tomó prestado a Ubú para una serie de textos que hizo ilustrar y editar. Él había editado ya en 1901, con textos del propio Alfred Jarry, el Almanach illustré du père Ubu Xxe siècle, acompañado por litografías de Pierre Bonnard. Pero el personaje de Vollard, aunque lleva el mismo nombre que el de Jarry, difiere en lo que representa: mientras el primer Ubú definía a la propia humanidad, con sus vicios y miserias, para Vollard el retratado será un grupo, una facción de claras connotaciones políticas y sociales ${ }^{16}$. Así lo aclara el propio marchante en sus memorias:

Lo que es, lo es como encarnación del "partido», de sus ideas, su programa, sus palabrastipo, sus fórmulas, prejuicios, divagaciones y odios, a los cuales se agarra como al ancla de la salvación, como a la boya de salvamento ${ }^{17}$.

Pero no sólo el editor Vollard mantuvo vivo al padre Ubú, sino que éste viviría una segunda juventud de manos del grupo surrealista. En 1936, Dora Maar (1907-1997), notable artista surrealista nacida el mismo año en el que muere Jarry, adopta a su criatura. Compañera senti-

\footnotetext{
${ }^{10}$ Richardson, John, Picasso. Una biografía. 1881-1906. Vol. I. Madrid, 1995, p. 349.

${ }^{11}$ Read, Peter, «Au Rendez-vous des poètes. Picasso, French Poetry and Theater, 1900-1906», pp. 215 y 222 , nota 47. En Picasso. The Early Years 1892-1906. Washington, 1997, pp. 211 a 223.

${ }^{12}$ Seckel-Klein, Hélène, Picasso collectionneur. París, 1998. Pp. 51 y 142.

${ }^{13}$ Cate, Phillip Dennis, «Fumism and Other Aspects of Parisian Modernism in Picasso's Early Drawings», pp. 136 y 140. En Picasso. The Early Years 1892-1906. Washington, 1997, pp. 133 a 141.

${ }^{14}$ Daix, Pierre, Dictionnaire Picasso. París, 1995, p. 489.

${ }^{15}$ Richardson, John, Op. cit., p. 333.

${ }^{16}$ Calcagni, Artemisia, «Ambroise Vollard: un mercante editore», pp. 18-19. En Catalogo completo dei libri illustrati dell'editore Ambroise Vollard. Milán, 1998, pp. 7 a 20.

${ }_{17}$ Vollard, Ambroise, Memorias de un vendedor de cuadros. Barcelona, 1983, p. 295.
} 
mental de Picasso, a quien había encontrado a principios de ese mismo año, expuso en el mes de mayo de 1936 la fotografía Retrato de Ubu [fig. 8] en la Exposición surrealista de objetos organizada por André Breton en la Galería Charles Ratton de París. Así opina Victoria Combalía sobre esta obra:

Ubú es una de las mejores, si no la mejor, representación plástica del personaje de Jarry, un dictador cruel, avaro y glotón. Un año después, Picasso daría una forma «ubuesca» al Caudillo en su aguafuerte Sueño y Mentira de Franco. Debía de tener la fotografía de Dora «in mente», pues el rostro de su dictador también posee un largo hocico y es tan monstruoso como esperpéntico y grotesco. Lo infantil del animal de Dora y lo infantil del dibujo picassiano, semejante al de una viñeta, les une por un momento ${ }^{18}$.

La misma fotografía tomaría parte al mes siguiente en la Primera Exposición Surrealista Internacional, inaugurada el 11 de junio de 1936 en Londres ${ }^{19}$, y allí se exhibiría colgada junto a una de las inquietantes cabezas de Picasso de 1930, con ese juego cruel de dientes en las llamadas bocas-vaginas, de evidentes connotaciones sexuales, de amor voraz [fig. 9].

Dora había fotografiado en un primerísimo plano el feto de un armadillo, o algo muy parecido (la cercanía al objeto hace más confusa su realidad, podría decirnos algún dogmático del surrealismo), y la imagen es estremecedora e impactante, fácil de recordar o de tener in mente, pero Picasso no esperaría un año para utilizar esa forma, ni lo haría sin antes convertirla en algo propio. Si hubo algo que parece que llamó la atención del pintor malagueño en la fotografía de Dora -o en el propio y supuesto feto del armadillo, pues hay que recordar que compartían vida artística y sentimental, que posiblemente eran la misma vida-, fueron las patas de largos y afilados dedos, cercanas por no decir pegadas a la cabeza del armadillo, del que apenas podemos ver un único ojo, oculto en las sombras del lateral izquierdo de su cabeza. Esa unión dedos-cabeza será convertida por Picasso en apéndices-ojos, en distintos trabajos que tienen por fecha ese mismo año de 1936, y podemos asociar esta forma con la clásica de un muñeco de guiñol, recordando además la idea de Jarry de Ubú como marioneta. No obstante, hay que aclarar que la creación de Picasso adoptará la forma de un títere de guante o funda, con el juego de los dedos pegados a la cabeza-dedo, mientras que Jarry pensaba y trabajaba con títeres de hilo o marionetas, como corroboran las palabras de su conferencia Sobre los títeres:

Los pequeños seres de madera viven, por ejemplo, en París, en casa de mi amigo Claude Terrase, el conocido músico, cuyas composiciones parecen complacerles sobremanera. Durante uno o dos años, Terrasse y yo mismo hemos sido los «Gulliver» de tales liliputienses. Les gobernábamos como conviene, por medio de hilos. Y Franc-Nohain, a quien encargamos componer una divisa para nuestro Teatro de Títeres, no pudo encontrar otra mejor que la más natural: «estrellas del filamento» ${ }^{20}$.

En una hoja del cuaderno de dibujo de Pierre Bonnard La vida del pintor [fig. 10] podemos ver representados, de pie y de izquierda a derecha, a Franc-Nohain, Alfred Jarry y Claude Terrase, mientras que sentado a la mesa se encuentra el propio Bonnard modelando una marioneta; al fondo, más artistas con guiñoles y el escenario. Es una de las más espléndidas descripciones que podemos encontrar de ese mundo de liliputienses y de sus gulliverianos artistas, todos alrededor del famoso teatro de títeres del cabaret Les 4z'Arts, donde se estrenó en 1901 Ubú en la colina, reducción a dos actos de Ubú rey.

\footnotetext{
${ }^{18}$ Combalía, Victoria, Dora Maar. La fotografía, Picasso y los surrealistas. Barcelona, 2002, p. 175.

${ }^{19}$ Penrose, Roland, 80 años de Surrealismo 1900-1981. Barcelona, 1981. La exposición se documenta ampliamente con fotografías de la sala en las pp. 63 a 67 , figs. 156,158 y 161 a 165 .

${ }^{20}$ Jarry, Alfred, Op. cit., p. 157.

$A E A$, LXXVIII, 2005, 312, pp. 353 a 368
} 

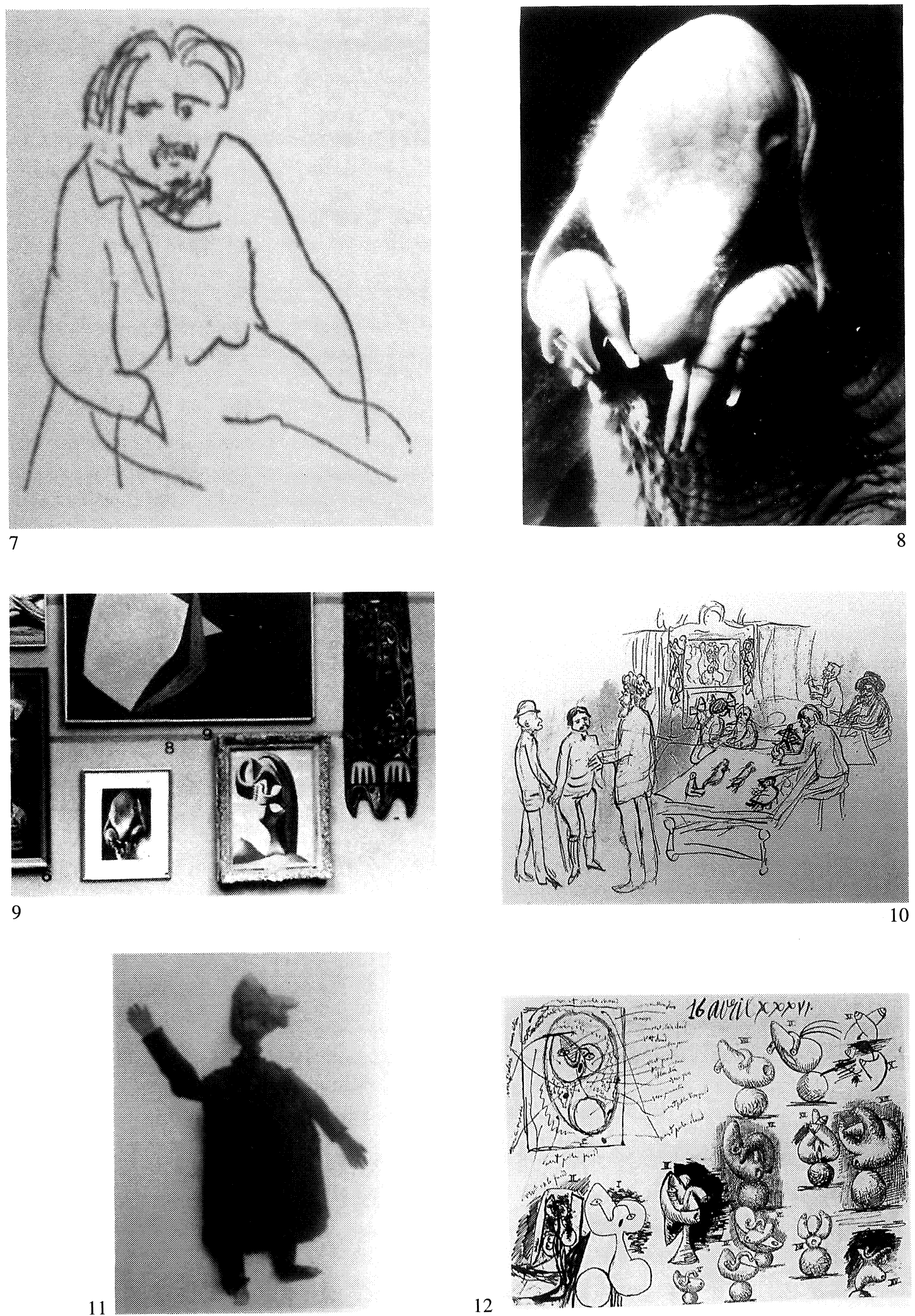

Lám. II. 
Y la propia marioneta de Ubú, modelada por el propio Alfred Jarry, es un títere de hilos, como nos demuestra la fotografía [fig. 11] que apareció en 1932 en la publicación de Paul Chauveau Alfred Jarry o el nacimiento, la vida y la muerte del Padre Ubú ${ }^{21}$.

Por lo tanto, ese aspecto de títere de guante hay que achacárselo al propio Picasso y a su trabajo con las formas, unido posiblemente a otras fuentes. Sabemos, por ejemplo, que Apollinaire era un gran aficionado al guiñol, miembro de la asociación Nos Marionettes, fundada por Gaston Cony durante la Primera Guerra Mundial y cuya sede estaba en París, en el Guiñol de la Guerra, parque de las Buttes-Chaumont, donde iba a ver las representaciones ${ }^{22}$.

Vamos ahora a asistir a la creación plástica de ese Ubú picassiano en una nueva versión. Es muy ilustrativa la hoja de dibujos que lleva por título Estudios: cabeza de mujer [fig. 12], y que Picasso realiza el 16-4-1936, un mes antes de que fuera expuesta por primera vez la fotografía de Dora Maar. En ella observamos una serie de bocetos, clasificados mediante números romanos, en los que el pintor está estudiando diversas representaciones de una volumétrica cabeza. Aunque éste sea un tema que ha trabajado continuamente, especialmente con ese tipo de deformaciones a partir de 1926, y no hay más que recordar las cabezas en yeso basadas en María Teresa Walter modeladas desde 1930, ninguno de los trabajos anteriores había mostrado hasta entonces los ojos de la figura como apéndices sobresalientes, cuestión que sólo solía ostentar la representación de la nariz de la figura. Aquí, en cambio, en los bocetos numerados como VIII y IX, junto a una base en forma de pera, los ojos se dibujan en los extremos del apéndice tubular que vemos sobre esta familiar pera. Pero son los dibujos X a XIV, y especialmente el XII, donde vemos claramente la intención del autor: los ojos van a estar situados sobre dos apéndices que sobresalen de la cabeza, y un tercer apéndice se destinará a la nariz. Si de nuevo observamos la fotografía realizada por Dora Maar, es eso lo que parece la imagen: tres apéndices saliendo de un cuerpo, dos patas y un hocico que Picasso está reconvirtiendo en dos ojos y una nariz, en una sintética recreación realizada entre los elementos observados y los conocidos. Además, el pintor insiste en la cavidad bucal como una cavidad abierta, penetrable, concavidad sexual en la convexidad exuberante de la forma, siguiendo sus modelos anteriores, pero él mismo va a abandonar esa alusión tan directa en un posterior trabajo. Se va a decidir por el estudio de la relación ojos-nariz, como podemos observar en un primer estadio en los apuntes de la parte izquierda de la hoja (resueltos de la misma manera que Jarry lo había hecho en su litografía de 1898, conectando los ojos mediante una línea-nariz).

El óleo Cabeza [fig. 13], fechado en el primero de mayo de 1936 -tanto en su parte posterior como en la zona inferior de su parte anterior Picasso ha anotado día, mes y año-, nos muestra un nuevo paso dentro del estudio de la nueva forma, con la particularidad de que la abertura de la boca, abismo lleno de misterios y peligros en otras ocasiones, ha sido reemplazada por una simpática línea curva que vivifica y nos hace agradable la representación de la cabeza. A partir de la boca, hacia arriba, observamos un primer apéndice enhiesto con un círculo en su extremo, que se asemeja al dedo gordo de una mano, con la palma y pulpejo como la parte inferior de esa cabeza (concomitancias entre el guiñol de guante y el armadillo), y un segundo apéndice de menores dimensiones, hacia abajo, con dos puntos en su extremo, que realmente sale de un tercer apéndice, casi horizontal y grueso, que también, como el primero, acaba en otro círculo. A ese juego de tres apéndices (ojo, nariz y ojo), Picasso superpone otra forma a la izquierda y en diagonal, texturizada mediante líneas que desembocan en un vértice y que representa una cabellera en la figura, típica en distintas representaciones de María Teresa Walter, y concretamente en las esculturas de 1931 realizadas en Boisgeloup (de tres de es-

\footnotetext{
${ }^{21}$ Reproducido en VV.AA. The Spirit of Montmartre. Cabarets, Humor and the Avant-Garde, 1875-1905. New Jersey, 1996. Fig. 150.

${ }^{22}$ Seckel, Hélène; Caizergues, Pierre, Picasso / Apollinaire. Correspondencia. Madrid, 2000, p. 169, nota 2, carta 124.
} 


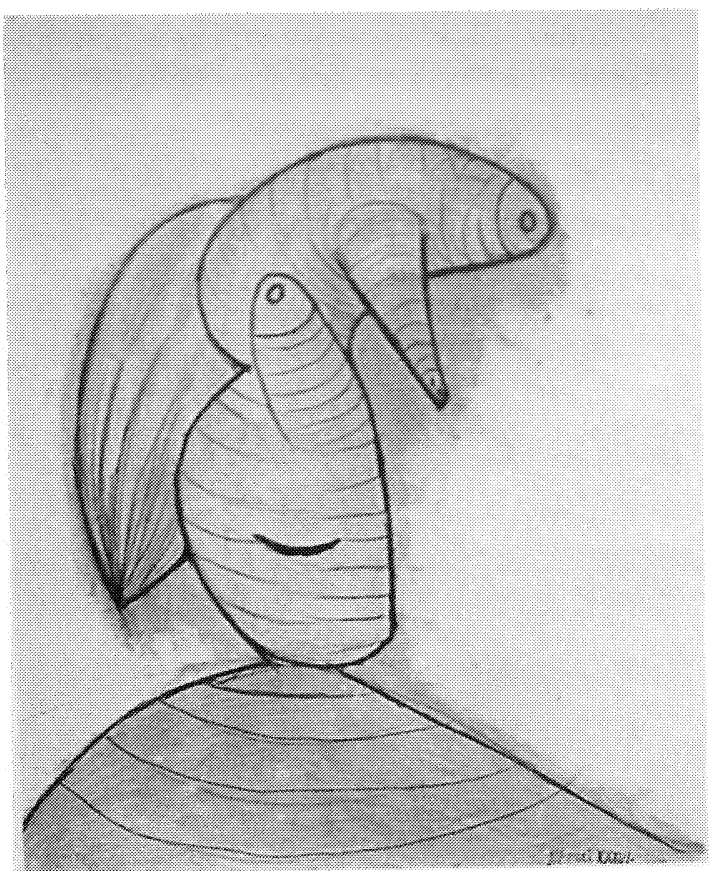

13

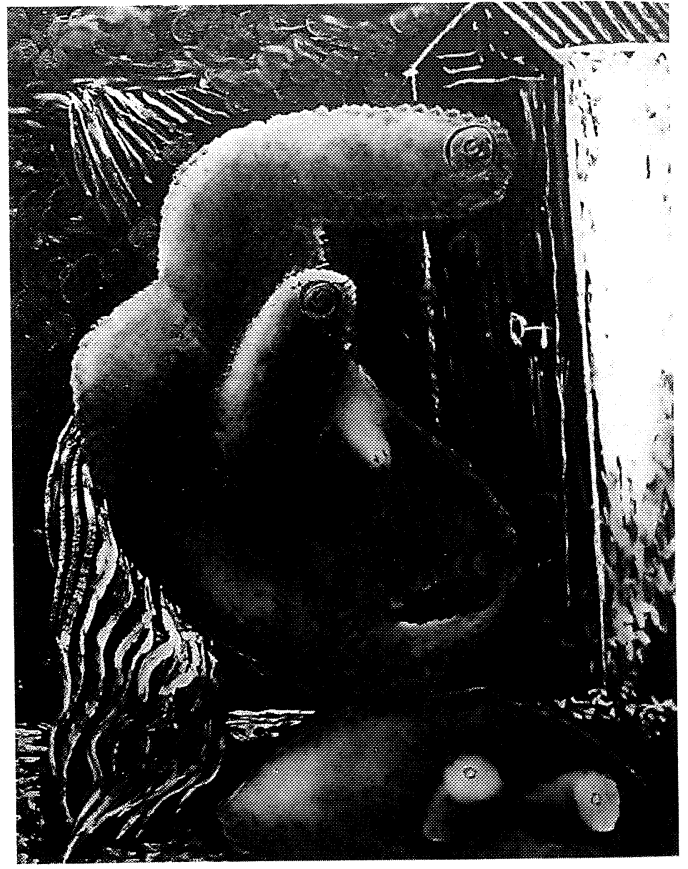

14

Lám. III.

tas cabezas Picasso realizó en 1937 vaciados en cemento para el Pabellón Español de la Exposición Internacional de París, las cuales se situaron en la segunda planta y en el jardín). Otro detalle nuevo, como son las líneas que van siguiendo en todo el retrato las curvas de las formas, podemos compararlas fácilmente con la textura de la piel del armadillo fotografiado por Dora Maar, que sigue este ritmo especialmente en su tronco y patas apenas formadas.

Como prueba de la unión sentimental y artística entre Dora y Picasso, entre 1936-1937 tenemos unas obras en colaboración, donde Dora se encarga de los aspectos técnicos y Picasso presta las formas a dicha técnica. Se trata del cliché-verre, placas de vidrio pintadas con óleo para ser después expuestas en el cuarto oscuro fotográfico y producir obras sobre papel fotográfico ${ }^{23}$. Muchacha delante de una caseta de playa (la bañista de Dinard) [fig. 14] repite la misma conocida cabeza con tres apéndices, pero en esta ocasión el artista la sitúa en un escenario muy conocido en su obra, con una caseta de playa cerrada y un cielo con nubes y rayos de sol saliendo de entre ellas, escenario explotado en toda una serie de trabajos que se desarrollan entre 1927 y 1938 y nos muestran figuras femeninas en el exterior junto a casetas de playa cerradas, guardando el misterio del inconsciente picassiano ${ }^{24}$. Hay una nueva incorporación a nuestra antigua forma, y es el detalle claramente femenino de dos cuasi-cilíndricos pechos de pezones-ojos.

Esta síntesis picassiana -una más- de Ubú, Apollinaire, armadillo o guiñol se ha convertido ante nuestros ojos en una representación femenina, en una época donde el autor está continuamente realizando retratos de María Teresa Walter y Dora Maar, amantes que se confunden en el tiempo y en varios de esos retratos, donde Dora es la mujer morena y María Teresa la rubia. Parece que Picasso está conjugando las expresiones universales que Alfred Jarry defen-

${ }^{23}$ Caws, Mary Ann. Dora Maar con y sin Picasso. Barcelona, 2000, p. 116.

${ }^{24}$ Gasman, Lydia, Mistery, magic and love in Picasso, 1925-1938. Picasso and the surrealist poets. Michigan, 1981, p. 266. 


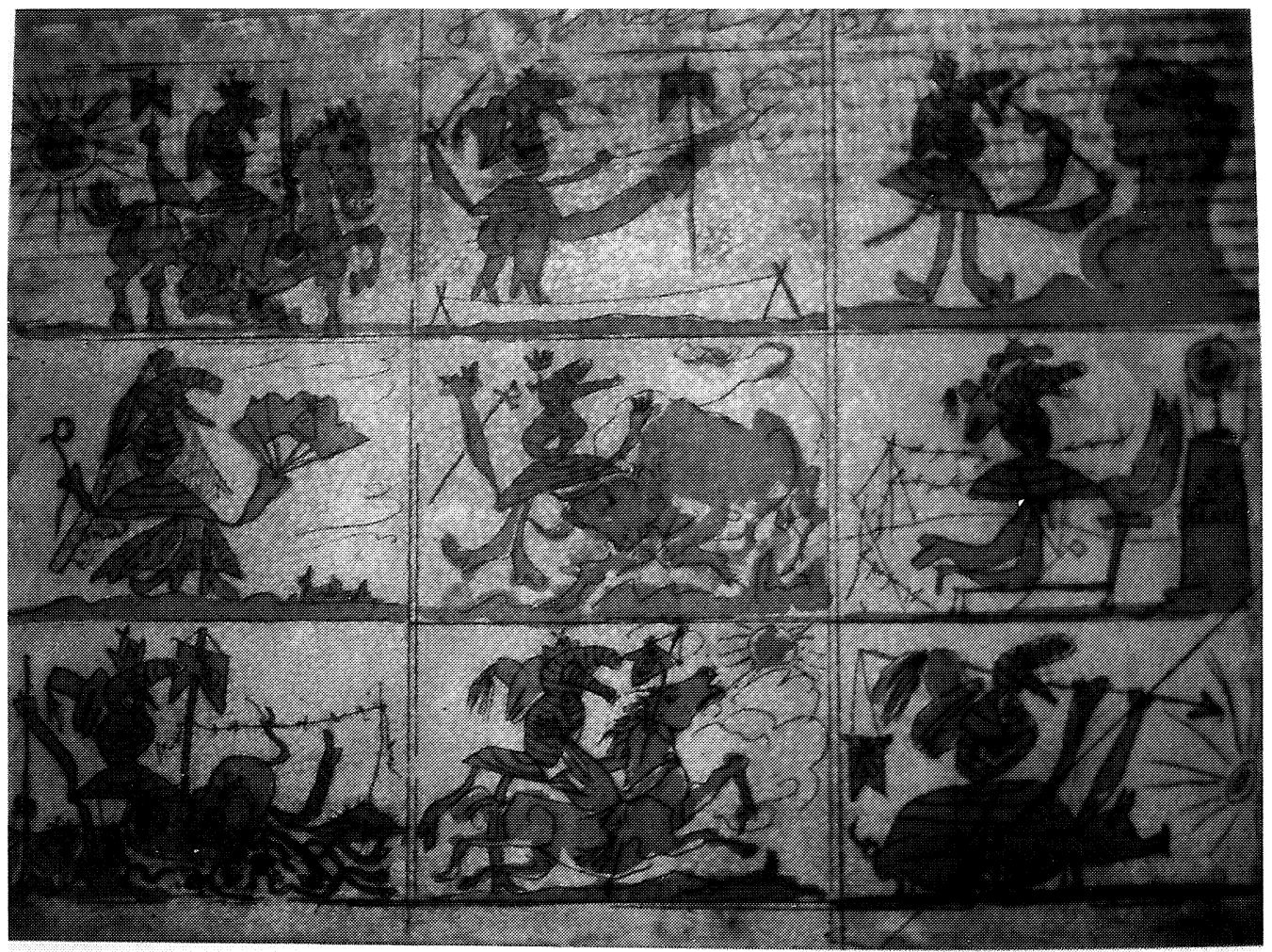

15

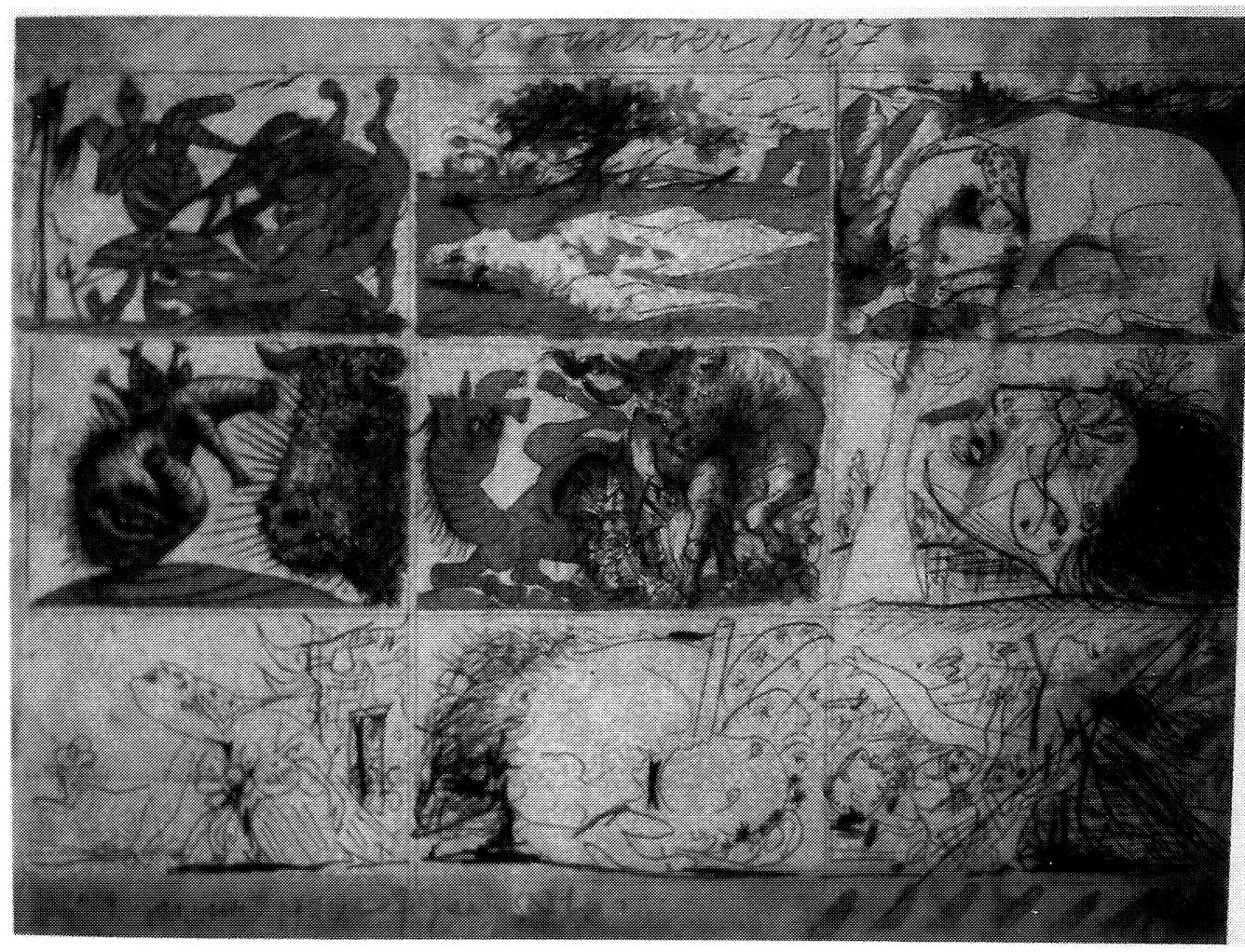

16

AEA, LXXVIII, 2005, 312, pp. 353 a 368 
diera con sus ideas de la máscara teatral ${ }^{25}$, con unos rasgos particulares, incluso podríamos decir muy personales.

Pero la vida sigue, y Ubú va a asistir a una nueva representación. Porque poco más de un mes después de la inauguración de la Primera Exposición Surrealista Internacional, donde Salvador Dalí tuvo que ser ayudado a salir del traje de buzo con el que pronunciaba su conferencia, concretamente el 17 de julio de 1936, comenzará en la ciudad de Melilla la sublevación que dará comienzo a la guerra civil española, cuando la policía sorprende una reunión conspiratoria de mandos militares y colaboradores civiles ${ }^{26}$. Ese interior burgués donde transcurrían las creaciones de Picasso acabará en llamas, y sus mujeres saldrán desesperadas al exterior, llorando sus hijos muertos.

Aunque algunos autores sitúan las conversaciones entre el gobierno de la República española y Picasso en el mismo mes de enero de 1937, parece claro que esta toma de contacto se había producido con anterioridad, por lo menos desde los días anteriores al nombramiento del pintor como director del Museo del Prado con fecha de 19 de septiembre de 1936. Es en diciembre cuando se le pide una colaboración concreta, como apoyo al gobierno legítimo de la República ${ }^{27}$. El trabajo correspondiente, comenzado el 8 de enero de 1937, es el grabado Sueño y Mentira de Franco, cuya edición consta originalmente de dos estampas y de otra hoja con una portada manuscrita en su anverso y un texto -un poema del propio Picasso- también manuscrito en su reverso, con una tirada de 1000 ejemplares ${ }^{28}$. Durante la Exposición Internacional de París, un ejemplar se exhibiría junto a otras publicaciones en una vitrina de la planta baja, especificando que se encontraba a la venta en el servicio de publicaciones del Pabellón Español, el cual fue inaugurado el 12 de julio de 1937.

Las planchas para dicho grabado, rayadas en junio de 1983 (anuladas para evitar una nueva edición), pertenecen actualmente a la colección Ludwig ${ }^{29}$. Fueron creadas durante los días 8 y 9 de enero, primero con un aguafuerte lineal y después completadas con un aguatinta tonal para crear las masas de grises, dejando los cuatro últimos recuadros de la segunda plancha sin trabajar, a los cuales se aplicaría un aguafuerte lineal el 7 de junio de 1937, cinco meses más $\operatorname{tarde}^{30}$. Si observamos estas planchas [figs. 15 y 16], podemos ver directamente en qué sentido fueron creadas por Picasso, como viñetas de una narración, en una secuencia de episodios que solemos contemplar al revés sobre el papel del grabado, puesto que se produce una inversión en el proceso de la estampación (hay que aclarar que la idea original era la de editar cada viñeta por separado).

En las estampas de Sueño y Mentira de Franco nos encontramos al personaje de mayo de 1936, ese armadillo-guiñol, pero la máscara de Ubú se ha transformado y se transforma viñeta a viñeta: bigote, toda suerte de aditamentos en su cabeza (coronas, medias lunas, birrete, tiara, peineta), pelos y hasta un hocico de cerdo, como vemos en la escena número trece [fig. 17].

Judi Freeman conecta al personaje creado por Picasso, especialmente en el recuadro comentado, con la historia escrita por Jarry y con la fotografía de Dora Maar ${ }^{31}$. Para Herschel

\footnotetext{
${ }^{25}$ Jarry, Alfred, Op. cit., p. 107.

${ }^{26}$ Thomas, Hugh, La Guerra Civil Española. Barcelona, 2003, pp. 239 a 241.

${ }^{27}$ Alix Trueba, Josefina, «El Pabellón español en la Exposición Internacional de París, 1937». En Pabellón español 1937. Exposición Internacional de París, pp. 10 a 171. Madrid, 1987, p. 100, notas 229 a 232.

${ }^{28}$ Goeppert, Sebastian; Goepert-Frank, Herma; Cramer, Patrick, Pablo Picasso. The Illustrated books: catalogue raisonné. Ginebra, 1983, pp. 82-83, n. ${ }^{\circ} 28$.

${ }^{29}$ VV.AA., Colección Ludwig. Barcelona, 1993, pp. 254 a 257.

${ }^{30}$ Geiser, Bernhard; Baer, Brigitte, Picasso peintre graveur. Catalogue raisonne de l'oeuvre grave et des monotypes. (7 vols. + addendum). Berna, 1986-1996. Concretamente, el tomo III Catalogue raisonne 1935-1945. Berna, 1986 (1. ${ }^{\mathrm{a}}$ ed.), pp. 106 a $110, \mathrm{n}^{\circ} 615$ y 616, y también Addendum 1899-1972. Berna, 1996 (1. ${ }^{\mathrm{a}}$ ed.), p. 38

${ }^{31}$ Freeman, Judi, Picasso and the weeping women. The years of Marie Therese Walter \& Dora Maar. Nueva York, 1994, p. 27.
}

$A E A$, LXXVIII, 2005, 312, pp. 353 a 368 


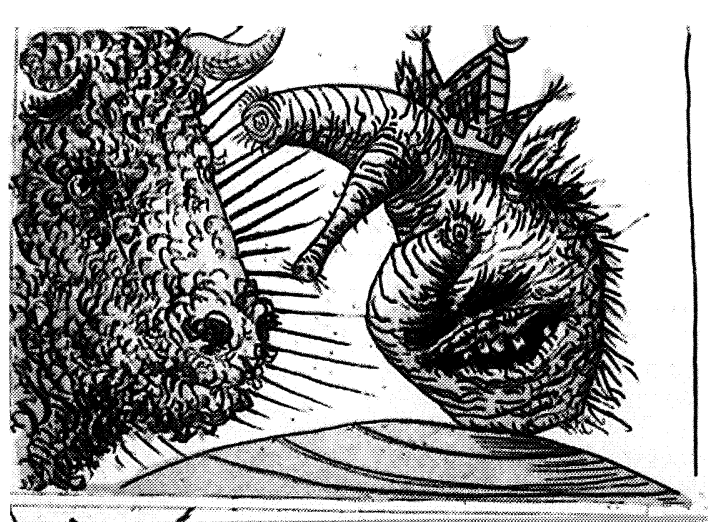

17

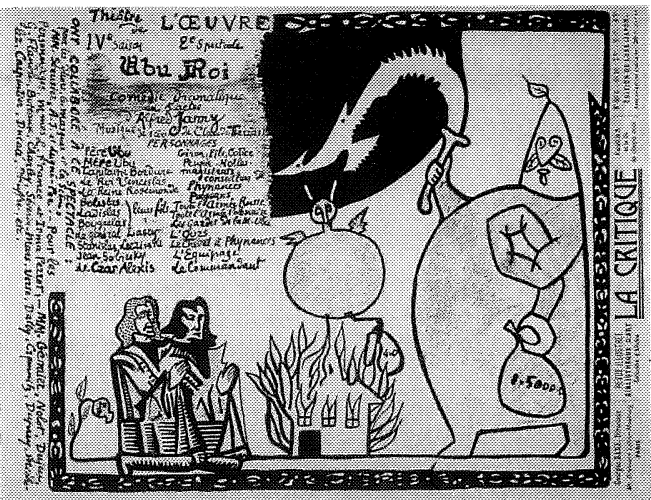

18

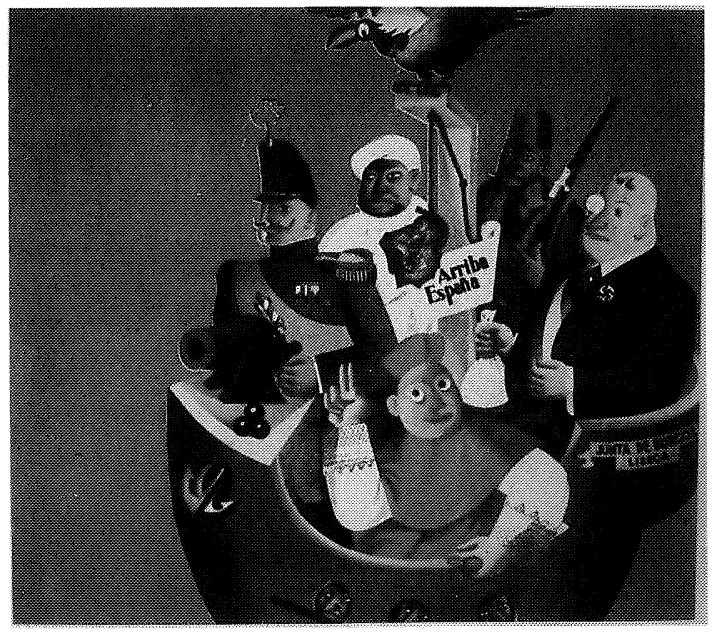

19

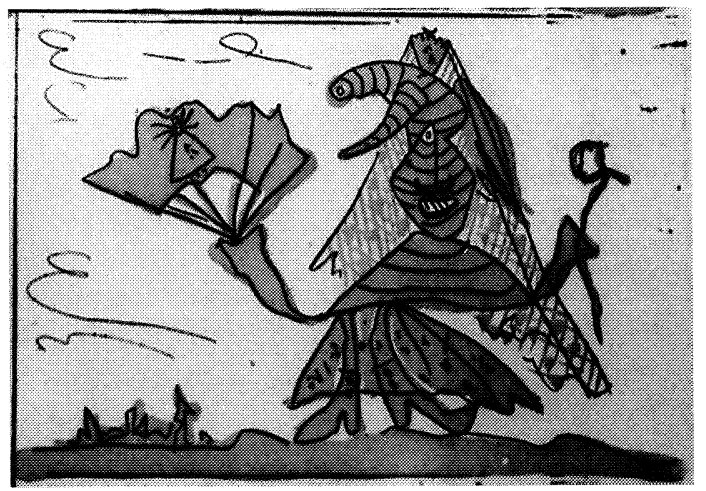

20

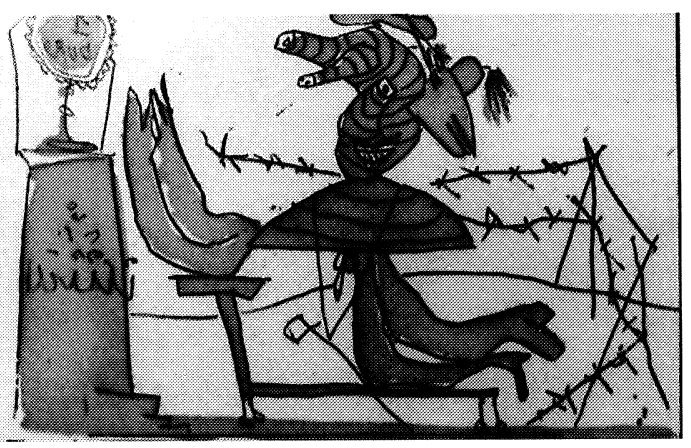

21

Lám. IV

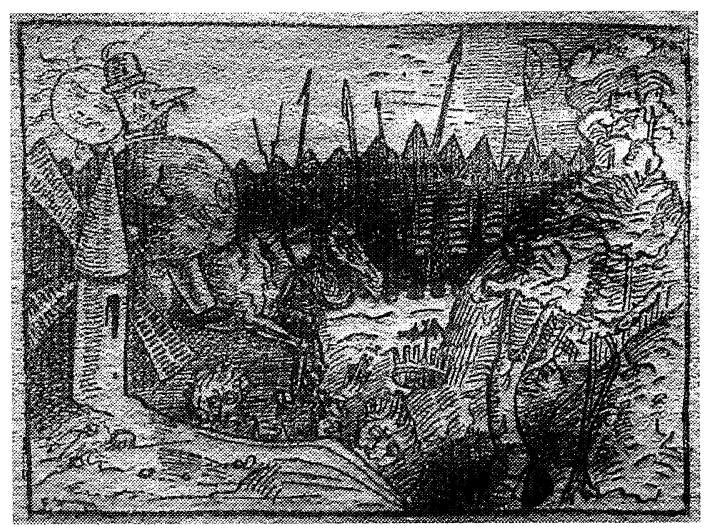

22

AEA, LXXVIII, 2005, 312, pp. 353 a 368 
Chipp Sueño y mentira de Franco retrata al dictador en forma de caricatura, con múltiples variantes y grotescos gestos que, además de evocar otros aspectos, nos hacen pensar en Ubú rey ${ }^{32}$. Parecen claros los puntos en común, tanto entre Franco y Ubú como entre otros dictadores, cercanos política y fisionómicamente de una u otra forma. Max Jacob, otro escritor amigo de Picasso y otro discípulo en su momento de Alfred Jarry, va a comparar en 1940, a las puertas de la Segunda Guerra Mundial, en una carta a Marcel Béalu, a Hitler con el personaje teatral, porque el alemán, a sus ojos, réalise $U$ bu roi ${ }^{33}$.

Por otro lado, los puntos en común entre la creación picassiana y el trabajo gráfico de Alfred Jarry también existen, sumados a otras referencias gráficas, aunque no se suelen citar.

En la litografía de 1896, insertada en el programa del Théâtre de l'Oeuvre [fig. 18], Jarry nos dibujaba a Ubú con un arma en una mano y el dinero en la otra, y frente a él representaba a dos personajes rodilla en tierra en actitud orante, sacados de la tradición de la pintura religiosa de la figura de los donantes. Al fondo, una casa en llamas. El autor parece describir gráficamente la escena segunda del tercer acto de su obra $\boldsymbol{U b u}$ roi, en la que Ubú asesina a los nobles, magistrados y hacendistas para quedarse con sus riquezas, pero en la realidad visualmente nos encontramos con la unión de dinero y poder, que aplasta a los hombres y destruye sus hogares, exactamente lo que era postulado en los carteles republicanos [fig. 19], con mayor simbología y panfletarismo, dándole a la Iglesia el papel de apoyo a la masacre: lo que Picasso describe en varias de sus viñetas con las particularidades de la guerra española, como aquella en la que Ubú-Franco, con espada y abanico con virgen, peineta con media luna y falda y velo, sirve de crítica al apoyo de la rancia aristocracia a los sublevados (escena número cuatro) [fig. 20]; en la viñeta sexta [fig. 21] encontramos a la misma figura arrodillada sobre un reclinatorio y adorando a una moneda de un duro; sobre su cabeza encontramos junto al tocado clásico árabe un sombrero episcopal.

Jarry creaba en 1895 una xilografía para la edición de César Anticristo [fig. 22], antecedente gráfico para su obra más conocida, puesto que prácticamente coincide con la escena tercera del acto cuarto de Ubú rey. En ella presentaba a su antihéroe en el campo de batalla, con el contraste del sol detrás sonriente y con el panzudo personaje sobre su caballo, el caballo de Phinanzas, derrengado por el esfuerzo y la falta de alimentación (Madre Ubú ha estado robando el dinero para su manutención). La primera viñeta dibujada por Picasso en Sueño y mentira de Franco [fig. 23] nos muestra al malvado personaje ubuesco sobre un caballo enfurecido y maltratado, puesto que además se nos muestran sus tripas saliendo de la herida abierta por la espuela del jinete; en una mano su espada y en la otra un estandarte con un motivo religioso, una virgen como las utilizadas por el bando sublevado en sus campañas, en lo que los historiadores han dado en llamar la movilización de las vírgenes; sobre la cabeza de Ubú-Franco una corona, y sobre ésta la media luna, simbolizando a las fuerzas militares del ejército español en Marruecos y a viejos enemigos de la República, como la Monarquía; atrás, el sol, teatral personaje, sonríe ante la escena. Paradójicamente, mientras el Ubú de Jarry acababa asesinando a las clases en el poder, nobles, magistrados y financieros, el Ubú de Picasso se vale de esas clases, a las que se une la Iglesia, para asesinar al pueblo.

Como Vollard en sus recreaciones y reencarnaciones, Picasso tenía la necesidad de particularizar a su Ubú, no sólo con un ridículo bigotito bajo su nariz, sino con la denuncia de sus alianzas fácticas. Y no fue el único de los intelectuales españoles comprometidos con el gobierno legítimo que utilizó de alguna manera al personaje de Alfred Jarry. María Teresa León, directora de Las Guerrillas del teatro, nos recuerda que el poeta Luis Cernuda tradujo para el

${ }^{32}$ Chipp, Herschel B., El Guernica de Picasso. Historia, transformaciones, significado. Barcelona, 1991, p. 12.

${ }^{33}$ Seckel, Hélène, Max Jacob et Picasso. París, 1994, p. 260, nota 4. 


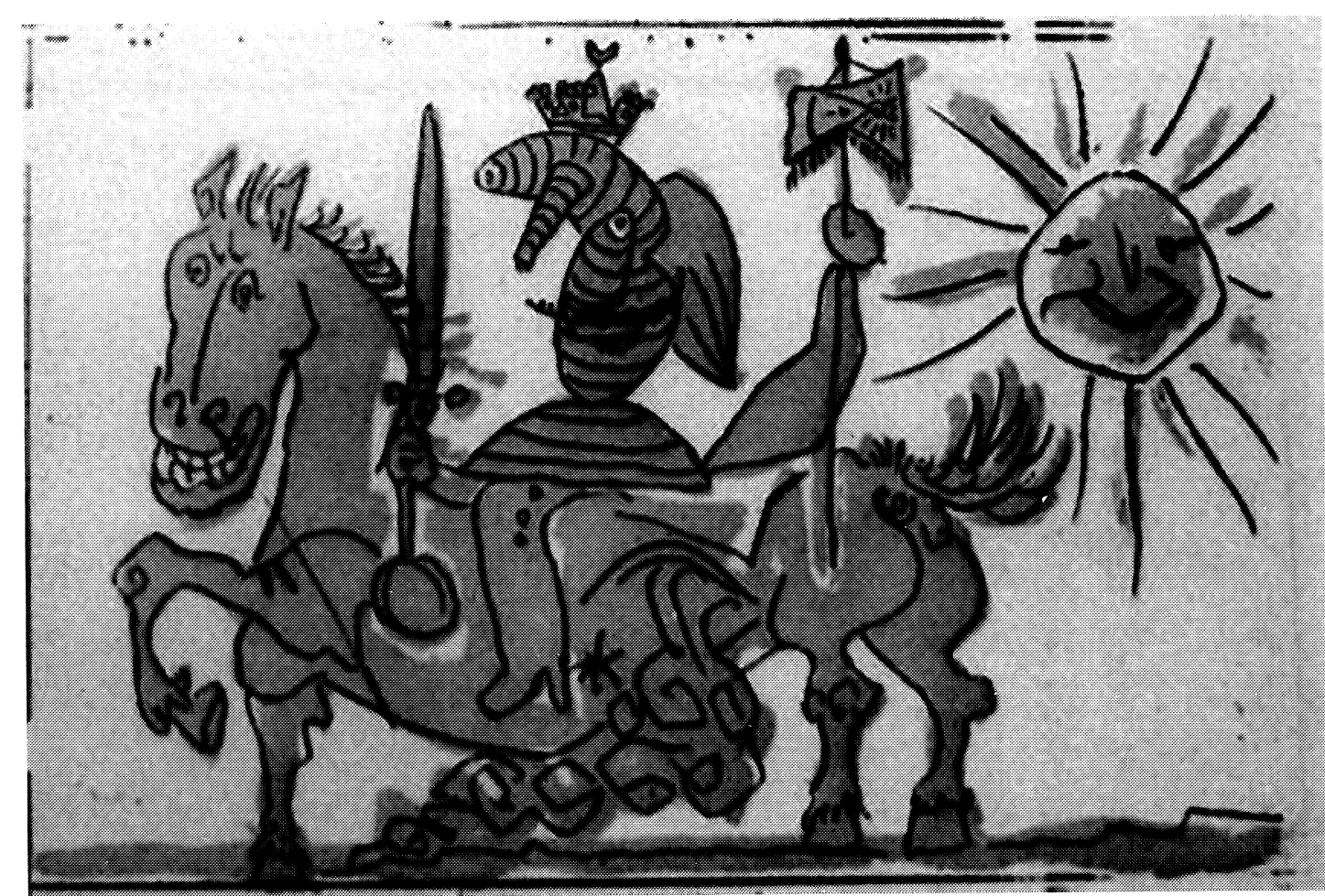

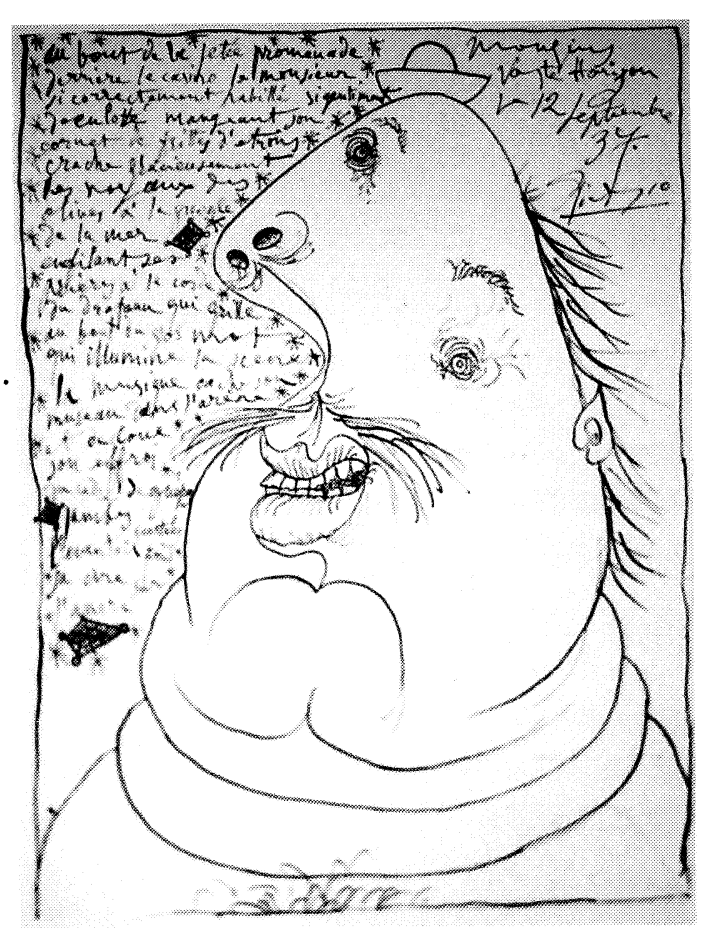

24

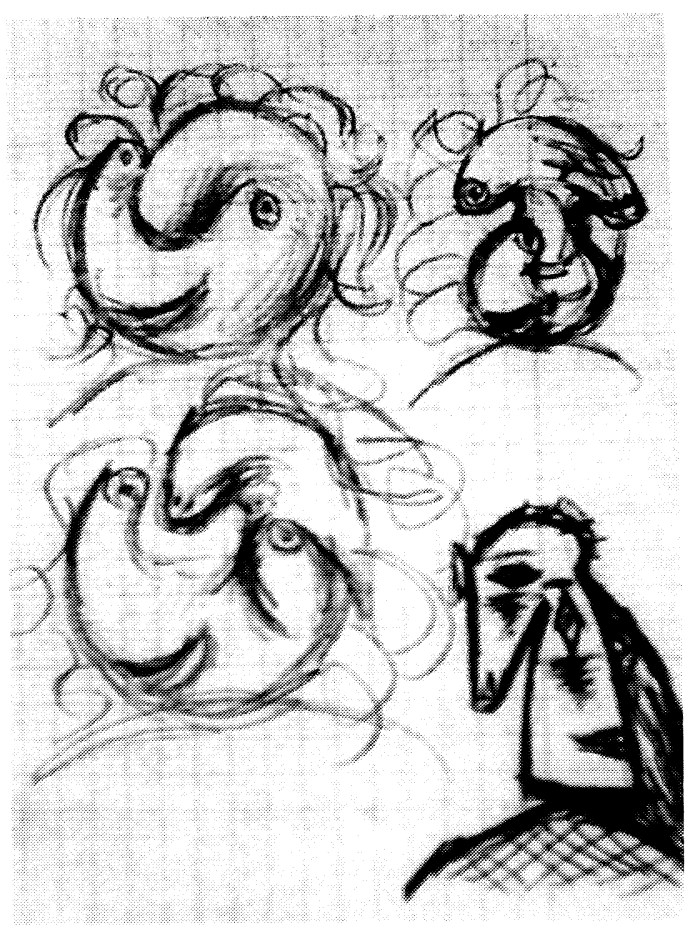

25

Lám. V.

AEA, LXXVIII, 2005, 312, pp. 353 a 368 
grupo de intelectuales comprometidos, para ser interpretado durante el conflicto, $\boldsymbol{U b} \boldsymbol{u}^{34}$. Aunque no se conoce dicha traducción, en un texto de 1937 el propio Cernuda incluye $\boldsymbol{U} b \boldsymbol{u}$ en un posible repertorio teatral para ese otoño excepcional de obuses sobre Madrid ${ }^{35}$.

El 12 de septiembre de 1937, unos tres meses después de terminar Sueño y Mentira de Franco, Picasso va a realizar un poema y un dibujo a tinta dedicados a ilustrar el programa de Ubú encadenado [fig. 24], la obra de Alfred Jarry que se iba a representar entre el 22 y 26 de septiembre de ese año en París, en la Comédie des Champs-Élysées ${ }^{36}$. Picasso colaboraba, junto a otros reconocidos artistas de vanguardia, en un directo homenaje al autor del personaje que nos ocupa; Max Ernst, por ejemplo, realizaría los cuatro decorados de la obra, uno por acto ${ }^{37}$. Centrándonos en el trabajo de Picasso, éste nos presenta a un personaje distinto al del grabado anterior, más cercano a los bocetos de 1905. Ante nuestros ojos toma forma un rostro humano, seboso, de carnosos labios y abundantes pliegues de grasa en su cuello, y con una evidente calvicie. El sombrero que anteriormente nos describía a tantos estamentos aliados contra la República es ahora un infantil gorrito, que habla también de la psicología del que lo porta. Incluso en el texto podemos encontrar un cambio de estilo: el pintor escribe en francés (el texto que acompañaba Sueño y Mentira de Franco fue escrito en español), y las fuertes palabras de los surrealistas versos no llegan a la violencia del anterior poema, donde había gritos de niños gritos de mujeres, alas rotas, dientes hincados en la arena y el caballo abierto, escabeche de espadas, lágrimas y en lagrimones, gotas de sangre... Ahora, Picasso nos habla de otro escenario, al final del paseo del malecón/ detrás del casino y de un execrable y ridículo personaje el señor/ tan correctamente vestido tan lindamente/ bajados sus pantalones comiendo su/ cucurucho de fritos de heces ${ }^{38}$. Despojado de referencias descriptivas del conflicto bélico español, ahora Ubú se podría parecer al Jarry maduro, burgués entronizado que nunca existió y que hubiera sido abominado por los surrealistas, como se encarga de resaltar André Breton, hablando del hombre gordo y grave, alcalde de pueblo al que los bomberos regalan jarrones de Sèvres ${ }^{39}$.

Tenemos que constatar, al consultar la catalogación de la obra picassiana a partir de estas fechas, que la marioneta Ubú desaparece de las manos del artista, guardada en el cajón biográfico de sus significados. Sólo en 1940 volveremos a encontrar rescatadas las formas de cabezas-apéndices en un cuaderno de dibujos ${ }^{40}$, donde el pintor parece recuperar estas formas en relación a un retrato femenino estudiado prolijamente, con unas trece hojas dedicadas a estos menesteres, aunque como podemos ver en el reverso de la hoja número 31 [fig. 25], el experimento acabará decantándose por un retrato femenino de busto con sólo el apéndice nasal exento. En estos comienzos de la cuarta década del siglo xx el pintor español ha quedado aislado de su patria por culpa de la victoria fascista, y se encuentra en un país que sufre la ocupación alemana, donde vive un difícil período de soledad e introspección, culpable seguramente de lo que tiene esta etapa de Royan de vuelta y desarrollo de formas consolidadas ya en su obra.

Como hemos visto desde 1905, Picasso a la hora de crear va analizando distintos modelos ajenos y propios, fusionándolos en un continuo trabajo de revisión que tiene siempre como objetivo la consecución de una obra original y extremadamente personalizada, cuasi biológica. Así, los límites del $\boldsymbol{U} b \boldsymbol{u}$ de Jarry han sido tan ensanchados en las manos del artista mala-

\footnotetext{
${ }^{34}$ León, María Teresa. Memoria de la melancolía. Barcelona, 1999, p. 326.

${ }^{35}$ Cernuda, Luis, Prosa II. Madrid, 1994, p. 135.

${ }^{36}$ Bernadac, Marie-Laure; Piot, Christine, Picasso écrits. París, 1989, pp. 176 y 177.

${ }^{37}$ Schneede, Uwe; Waldberg, Patrick; Waldman, Diane, Max Ernst. Barcelona, 1977, pp. 207 y 441.

${ }^{38}$ En el original: Au bout de la jetée promenade/ derrière le casino le monsieur/ si correctement habillé si gentiment/ déculotté mangeant son/ cornet de frites d'étrons.

${ }^{39}$ Bretón, André, Los pasos perdidos. Madrid, 1995, p. 37.

${ }^{40}$ Léal, Brigitte. Musée Picasso. Carnets. Catalogue des dessins. París, 1996. Cat. 42.
}

AEA, LXXVIII, 2005, 312, pp. 353 a 368 
gueño que no podemos objetivamente hablar de una simple utilización del personaje, sino del empleo de algunas de sus características, y entre éstas han atraído más la atención de Picasso los aspectos plásticos que los literarios (junto a la posibilidad de enriquecerlo con otras aportaciones de muy diverso origen). Asimismo, en diversos momentos de 1937, la obra gráfica de Jarry no ha sido la base del proceso creador, sino que ha actuado como una aportación más al desarrollo formal de un tema. 